\title{
Surgical treatment of an anterior cranial fossa dural fistula
}

Tratamento cirúrgico de uma fístula dural da fossa craniana anterior

Leila Maria Da Róz, Bernardo Assumpção de Monaco, Djalma Felipe da Silva Menendez, César Casarolli, Eberval Gadelha Figueiredo, Manoel Jacobsen Teixeira

A 48-year-old man presented headaches in the last two months, and no neurological deficits.

The computed tomography (CT) scan revealed an intraparenchymal hemorrhage localized in right frontal lobe ${ }^{1}$.

The magnetic resonance (MR) showed the lesion included middle frontal gyrus, fronto-orbital region and gyrus rectus (Fig 1).
Diagnostic cerebral angiography (DCA) demonstrated intracranial dural arteriovenous fistulas (DAVF) classified as Borden $\mathrm{IA}^{2-5}$, a single fistula with venous drainage directly into dural venous sinus or meningeal vein and antegrade flow (Fig 1).

The DAVF was occluded after a right frontotemporoparietal craniotomy, and a DCA, one year after the procedure, showed no residual fistula (Fig 2).
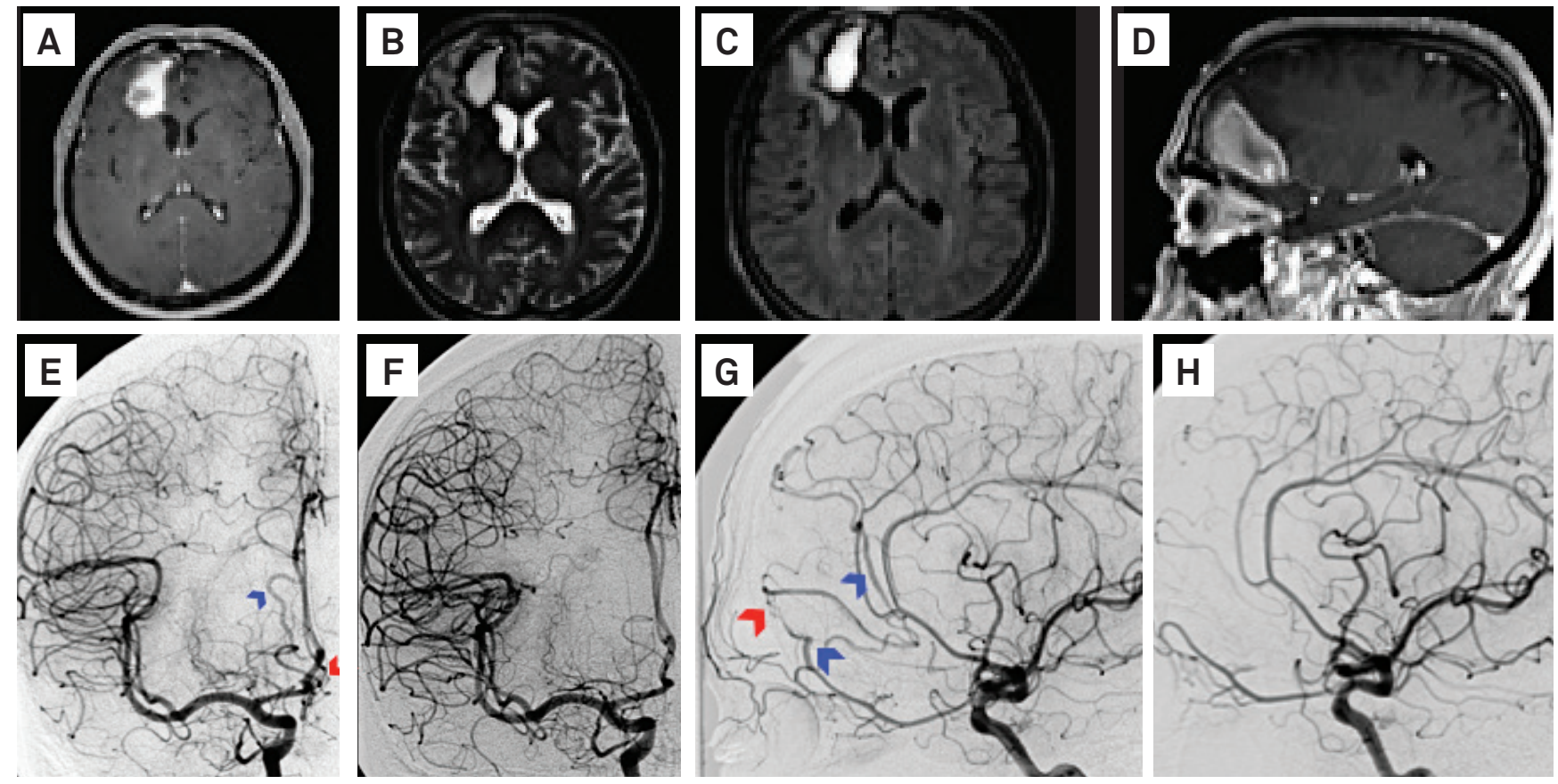

Fig 1. (A - C) Magnetic Resonance (MR) images axial view; T1, T2 and Flair sequences respectively. The image presents a hyperintense lesion in both T1 and T2 images, and a hypointense peripheric halo in T2, suggesting a subacute evolution. T2 and FLAIR images had a peripheric hypersinal due to edema, contributing to the mass effect and a discrete compression of the frontal horn of the lateral ventricle. (D) T1 sequence, sagital view. $(E-H)$ Digital Angiography. The DAVF involves the right frontopolar artery and a dural vein of the anterior fossa. There is drainage to the falcine parasagital vein and from this to the superior sagital sinus. (E and G) Right Internal Carotid Angiography: note red arrow pointing the anomalous shunt and blue arrow showing anomalous drainage vessels. ( $F$ and $H$ ) Angiography post-surgery: no shunt or anomalous draining vessels.

Departamento de Neurologia, Divisão de Neurocirurgia do Hospital das Clínicas da Universidade de São Paulo (USP), São Paulo SP, Brazil. Correspondence: Leila Maria Da Róz; Avenida Dr. Enéas Carvalho Aguiar 255; 05403-000 São Paulo SP - Brasil; E-mail: leilaroz@hotmail.com Conflict of interest: There is no conflict of interest to declare.

Received 07 November 2012; Received in final form 11 December 2012; Accepted 18 December 2012. 

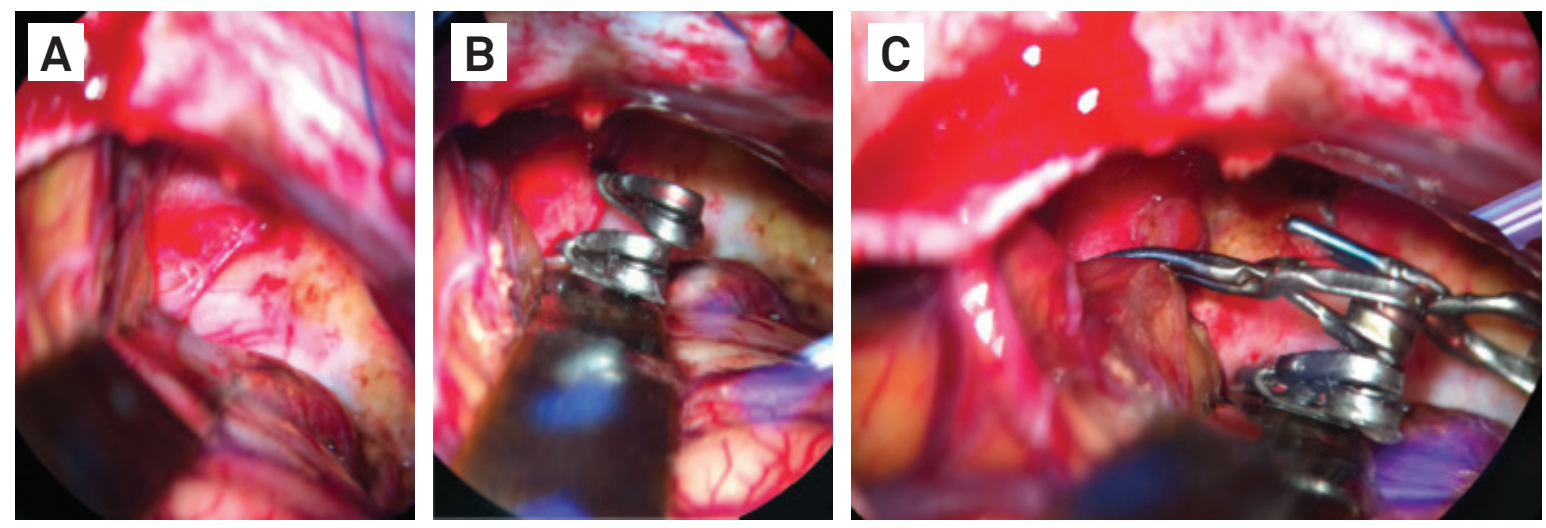

Fig 2. Intraoperative pictures. (A) shows the drainage vein, (B) shows its ligation with two aneurysm clips and (C) the arterial component being ligated also with an aneurysm clip and after the coagulation and cut of the venous component.

\section{REFERENCES}

1. Borden JA, Wu JK, Shucart WA. A proposed classification for spinal and cranial dural arteriovenous fistulous malformations and implications for treatment. J Neurosurg 1995;82:166-179.

2. Cognard C, Gobin YP, Pierot L, et al. Cerebral dural arteriovenous fistulas: clinical and angiographic correlation with a revised classification of venous drainage. Radiology 1995;194:671-680.

3. Davies MA, TerBrugge K, Willinsky R, Coyne T, Saleh J, Wallace MC. The validity of classification for the clinical presentation of intracranial dural arteriovenous fistulas. J Neurosurg 1996;85:830-837.

4. Gomez J, Amin AG, Gregg L, Gailloud P. Classification schemes of cranial dural arteriovenous fistulas. Neurosurg Clin N Am 2012;23:55-62.

5. Reul J, Thron A, Laborde G, Bruckmann H. Dural arteriovenous malformations at the base of the anterior cranial fossa: report of nine cases. Neuroradiology 1993;35:388-393. 